\title{
Cost Conversations Between Primary Care Providers and Patients with Expanded Medicaid Coverage
}

\author{
Renuka Tipirneni, MD, MSc ${ }^{1,2}$, Minal R. Patel, $P h D, M P H^{1,3}$, Matthias A. Kirch, $M S^{1}$, and \\ Susan D. Goold, MD, MHSA, MA
}

'Institute for Healthcare Policy and Innovation, University of Michigan, Ann Arbor, MI, USA; ${ }^{2}$ Division of General Medicine, Department of Internal Medicine, University of Michigan, Ann Arbor, MI, USA; ${ }^{3}$ School of Public Health, University of Michigan, Ann Arbor, MI, USA; ${ }^{4}$ Center for Bioethics and Social Sciences in Medicine, University of Michigan, Ann Arbor, MI, USA.

KEY WORDS: out-of-pocket costs; health insurance; medicaid; physician-
patient communication.

J Gen Intern Med 33(11): 1845-7

DOI: $10.1007 / \mathrm{s} 11606-018-4551-2$

(c) Society of General Internal Medicine 2018

\section{INTRODUCTION}

Patients face increasing out-of-pocket (OOP) costs for healthcare, ${ }^{1}$ which have been associated with medication non-adherence and poor health outcomes. ${ }^{2,3}$ While lowincome patients may frequently have concerns about OOP costs - even if they have insurance with generous covered benefits - they may not raise cost concerns with physicians. Little is known about cost conversations between primary care providers (PCPs) and low-income patients. Our objective was to determine the frequency, predictors, and PCPs' perceptions of the impact of cost conversations with low-income patients in an expanded Medicaid program in Michigan ("Healthy Michigan Plan" [HMP]), a state program for adults ages 1964 with incomes $\leq 138 \%$ of the federal poverty level (FPL) and includes limited cost-sharing for beneficiaries $(\leq 2 \%$ of income).

\section{METHODS}

We conducted a mailed survey of all PCPs caring for $\geq 12$ HMP patients in June-November 2015. The sample was derived from the Michigan Department of Health and Human Services (MDHHS) Medicaid claims data warehouse and included both physician and non-physician (nurse practitioner or physician assistant) PCPs. The University of Michigan and MDHHS institutional review boards considered the study exempt.

Respondents were asked, "Have you ever discussed out-ofpocket medical costs with a HMP patient?" Respondents who answered "yes" were asked: (a) "Thinking of the most recent time you discussed out-of-pocket medical expenses with a HMP patient, who brought up the topic?" and (b) "Thinking of the most recent time you discussed out-of-pocket medical

Published online July 11, 2018 expenses with a HMP patient, did the conversation result in a change in the management plan for the patient?"

Descriptive statistics report responses to individual survey items. $\chi^{2}$ and logistic regression analyses were used to examine the unadjusted and adjusted associations between PCPs' personal, professional, and practice characteristics, and (1) the likelihood of cost conversations, and (2) change in management due to cost conversations. Statistical analyses were performed using Stata version 14.2; two-sided $p<0.05$ was considered significant.

\section{RESULTS}

The response rate was $56 \%(N=2104)$. Respondent PCPs were $55 \%$ male, $79 \%$ White, 5\% Black, 2\% Hispanic/Latino, and $83 \%$ physicians. Four hundred forty-five (22\%) said that they had discussed OOP medical costs with a HMP patient. Of those who had cost conversations, the topic was brought up $56 \%$ of the time by the patient, $39 \%$ by the PCP, $4 \%$ by somebody else in the practice (e.g., clerical or nursing staff), and $1 \%$ by another person. When a cost conversation occurred, $56 \%$ of PCPs reported it resulted in a change in management.

Cost conversations were more frequent among female, White, and non-physician PCPs, those with prior care for the underserved, working in federally qualified health centers, or in practices with Medicaid/uninsured-predominant payer mixes or rural settings (Table 1). Changes in management due to cost conversations were more common among non-physician PCPs, those with fewer years in practice and in rural settings. In multivariable regression analyses, the adjusted odds of cost conversations were greater for White, Hispanic/Latino, and non-physician PCPs, and those with Medicaid/uninsuredpredominant payer mixes (Table 2). PCPs with fewer years in practice or in non-suburban settings had greater adjusted odds of management changes due to cost conversations.

\section{DISCUSSION}

Only one in five PCPs reported conversations about out-ofpocket medical costs with low-income Medicaid patients. The frequency of cost conversations we observed appears on the 
Table 1 Association of PCP Personal, Professional, and Practice Characteristics with Frequency of Cost Conversations and Change in Clinical Management Due To Cost Conversations

\begin{tabular}{|c|c|c|c|}
\hline PCP characteristics & $\begin{array}{l}\text { All respondents } \\
N(\text { col \%) }\end{array}$ & $\begin{array}{l}\text { Cost conversations } \\
n(\text { row } \% \text { s) }\end{array}$ & $\begin{array}{l}\text { Change in management } \\
\text { due to cost conversation } \\
n(\text { row } \% \dagger)\end{array}$ \\
\hline Total & $2104(100 \%)$ & $445 / 1988(22.4 \%)$ & $248 / 440(56.4 \%)$ \\
\hline \multicolumn{4}{|l|}{ Personal characteristics } \\
\hline \\
\hline Male & $1165(55.4 \%)$ & $227 / 1107(20.5 \%)^{\S}$ & $118 / 224(52.7 \%)$ \\
\hline Female & $939(44.6 \%)$ & $218 / 881(24.7 \%)$ & $130 / 216(60.2 \%)$ \\
\hline \multicolumn{4}{|l|}{ Racet } \\
\hline White & $1579(79.1 \%)$ & $367 / 1145(24.3 \%)^{\mathrm{II}}$ & $204 / 364(56.0 \%)$ \\
\hline Black/African American & $92(4.6 \%)$ & 14/91 (15.4\%) & $8 / 14(57.1 \%)$ \\
\hline Asian/Pacific Islander & $218(10.9 \%)$ & $25 / 204(12.3 \%)$ & $14 / 23(60.9 \%)$ \\
\hline Other/more than one & $107(5.4 \%)$ & $18 / 103(17.5 \%)$ & $10 / 18(55.6 \%)$ \\
\hline \multicolumn{4}{|l|}{ Ethnicitył } \\
\hline Hispanic/Latino & $46(2.3 \%)$ & $15 / 45(33.3 \%)$ & $8 / 15(53.3 \%)$ \\
\hline Not Hispanic/Latino & $1978(97.7 \%)$ & $416 / 1475(22.0 \%)$ & $234 / 411(56.9 \%)$ \\
\hline \multicolumn{4}{|l|}{ Professional characteristics } \\
\hline \multicolumn{4}{|l|}{ Provider type } \\
\hline Physician & $1750(83.2 \%)$ & $337 / 1653(20.4 \%)^{\mathbb{I}}$ & $180 / 333(54.1 \%)$ \\
\hline \multirow{2}{*}{\multicolumn{4}{|c|}{ Specialty }} \\
\hline & & & \\
\hline Family medicine & $1123(53.4 \%)$ & $230 / 1064(21.6 \%)^{\mathrm{II}}$ & $119 / 228(52.2 \%)^{\S}$ \\
\hline Internal medicine & $574(27.3 \%)$ & $96 / 538(17.8 \%)$ & $58 / 94(61.7 \%)$ \\
\hline Other physician specialty & $53(2.5 \%)$ & $11 / 51(21.6 \%)$ & $3 / 11(27.3 \%)$ \\
\hline Non-physician (NP or PA) & $354(16.8 \%)$ & $108 / 335(32.2 \%)$ & 68/107 (63.6\%) \\
\hline \multicolumn{4}{|l|}{ Years in practice } \\
\hline$<10$ years & $520(25.9 \%)$ & $126 / 502(25.1 \%)$ & $87 / 125(69.6 \%)^{\S}$ \\
\hline $10-20$ years & $676(33.7 \%)$ & $134 / 644(20.8 \%)$ & $72 / 133(54.1 \%)$ \\
\hline$>20$ years & $810(40.4 \%)$ & $172 / 753(22.8 \%)$ & $84 / 169(49.7 \%)$ \\
\hline \multicolumn{4}{|l|}{ Prior care for underserved patientst } \\
\hline Yes & $1153(57.0 \%)$ & $284 / 1102(25.8 \%)^{\mathrm{II}}$ & $161 / 282(57.1 \%)$ \\
\hline No & $871(43.0 \%)$ & $151 / 834(18.1 \%)$ & $82 / 148(55.4 \%)$ \\
\hline \multicolumn{4}{|l|}{ Practice characteristics } \\
\hline \multicolumn{4}{|l|}{ Practice sizet } \\
\hline Small $(\leq 5$ providers $)$ & $1157(57.5 \%)$ & $252 / 1087(23.2 \%)$ & $141 / 250(56.4 \%)$ \\
\hline Large ( $>5$ providers) & $855(42.5 \%)$ & $181 / 820(22.1 \%)$ & $103 / 178(57.9 \%)$ \\
\hline \multicolumn{4}{|l|}{ FQHC practice } \\
\hline Yes & $311(14.9 \%)$ & $94 / 299(31.4 \%)^{\mathrm{qI}}$ & $58 / 94(61.7 \%)$ \\
\hline No & $1770(85.1 \%)$ & $347 / 1669(20.8 \%)$ & $188 / 343(54.8 \%)$ \\
\hline \multicolumn{4}{|l|}{ University/teaching hospital practice } \\
\hline Yes & $276(13.4 \%)$ & $48 / 263(18.3 \%)$ & $27 / 47(57.5 \%)$ \\
\hline No & $1786(86.6 \%)$ & $388 / 1687(23.0 \%)$ & $217 / 384(56.5 \%)$ \\
\hline \multicolumn{4}{|l|}{ Hospital-based practice (non-teaching) $!$} \\
\hline Yes & $643(31.2 \%)$ & $134 / 609(22.0 \%)$ & $82 / 132(62.1 \%)$ \\
\hline \multirow{2}{*}{\multicolumn{4}{|c|}{ Payer mix }} \\
\hline & & & \\
\hline Medicaid/uninsured predominant & $689(36.0 \%)$ & $177 / 670(26.4 \%)^{\S}$ & $104 / 177(58.8 \%)$ \\
\hline \multirow{2}{*}{\multicolumn{4}{|c|}{ Urbanicity }} \\
\hline & & & \\
\hline Urban & $1584(75.3 \%)$ & $312 / 1492(20.9 \%)^{\S}$ & $168 / 309(54.4 \%)^{\S}$ \\
\hline Suburban & $193(9.2 \%)$ & $42 / 185(22.7 \%)$ & $20 / 42(47.6 \%)$ \\
\hline Rural & $327(15.5 \%)$ & $91 / 311(29.3 \%)$ & $60 / 89(67.4 \%)$ \\
\hline
\end{tabular}

*Row percent among respondents who answered the question about cost conversations $(N=1988)$

tRow percent among those respondents who had a cost conversation $(N=440)$

$t$ All respondents column does not sum to 2104 due to skipped responses

${ }_{s} p<0.05$

$p<0.001$

low-end range of 4-65\% observed in other studies examining cost conversations in the general population. ${ }^{4}$

However, half of PCPs who had cost conversations reported a resulting change in management, attesting to the value of such conversations for patient-centered care, even for Medicaid patients with generous covered benefits and limited cost-sharing. Although OOP costs may be declining for some groups after Affordable Care Act coverage expansion, even nominal OOP costs may be considerably burdensome for low-income patients. $^{2,3}$
Thus, greater investment is needed to improve the frequency and quality of cost conversations. ${ }^{5,6}$

Potential study limitations include self-reported outcomes, survey questions limited to Medicaid expansion patients in a single state, a sample enriched for PCPs caring for at least 12 Medicaid expansion patients, the study's focus on assessing cost conversations from the PCP perspective, and the absence of data on types of changes in management. Frequency of cost conversations may differ for other healthcare provider or patient groups, or in other states. Future research may examine 
Table 2 Multivariable Association of PCP Personal, Professional, and Practice Characteristics with Likelihood of Cost Conversations, and Likelihood of Change in Clinical Management Due To Cost Conversations

\begin{tabular}{|c|c|c|}
\hline \multirow[t]{2}{*}{ PCP characteristics } & \multicolumn{2}{|l|}{$\begin{array}{l}\text { Adjusted odds ratio* } \\
\text { (95\% CI) }\end{array}$} \\
\hline & Odds of cost conversation & $\begin{array}{l}\text { Odds of change in management } \\
\text { due to cost conversation } \dagger\end{array}$ \\
\hline \multicolumn{3}{|l|}{ Personal characteristics } \\
\hline Male gender & $0.82(0.63-1.05)$ & $0.91(0.58-1.41)$ \\
\hline \multicolumn{3}{|l|}{ Race } \\
\hline White & [ref] & [ref] \\
\hline Black/African American & $0.52(0.28-0.96) \ddagger$ & $0.92(0.29-2.93)$ \\
\hline Asian/Pacific Islander & $0.43(0.27-0.70)+$ & $1.37(0.54-3.46)$ \\
\hline Other/More than one & $0.65(0.36-1.17)$ & $1.60(0.52-4.94)$ \\
\hline Ethnicity, Hispanic/Latino & $2.11(1.08-4.12) \dagger$ & $0.93(0.31-2.77)$ \\
\hline \multicolumn{3}{|l|}{ Professional characteristics } \\
\hline Provider type, physician (ref = non-physician) & $0.71(0.51-0.99) \div$ & $0.96(0.54-1.73)$ \\
\hline \multicolumn{3}{|l|}{ Years in practice } \\
\hline$<10$ years & [ref] & [ref] \\
\hline $10-20$ years & $0.81(0.60-1.09)$ & $0.52(0.30-0.89) \ddagger$ \\
\hline$>20$ years & $1.04(0.77-1.42)$ & $0.47(0.27-0.82)$ \\
\hline \multicolumn{3}{|l|}{ Practice characteristics } \\
\hline \multicolumn{3}{|l|}{ Payer mix } \\
\hline Medicaid/uninsured predominant & $1.31(1.02-1.69) \div$ & $0.95(0.60-1.51)$ \\
\hline Private/Medicare/other predominant & [ref] & [ref] \\
\hline \multicolumn{3}{|l|}{ Urbanicity } \\
\hline Urban & $0.82(0.60-1.11)$ & $0.62(0.35-1.11)$ \\
\hline Suburban & $0.70(0.45-1.11)$ & $0.41(0.18-0.95)$ \\
\hline Rural & [ref] & [ref] \\
\hline
\end{tabular}

*Each column represents a different multivariable model

tOdds of change in management among those respondents who had a cost conversation $t p<0.05$

$s_{p}<0.001$

facilitators and barriers to cost conversations, and resulting management changes.

ACKNOWLEDGMENTS: We gratefully acknowledge the contribution of other evaluation team members who contributed to survey development and administration including Eric G. Campbell, $\mathrm{PhD}$; John Z. Ayanian, MD MPP; Cengiz Salman, MA; Sarah J. Clark, MPH; Tammy Chang, MD MPH MS; Adrianne N. Haggins, MD MSc; Edith C. Kieffer, PhD; Lisa Szymecko, JD PhD; Sunghee Lee, PhD; Erica Solway, PhD MPH MSW; Erin Beathard, MPH MSW; and Zachary Rowe, BS.

Corresponding Author: Renuka Tipirneni, MD, MSc; Division of General Medicine, Department of Internal Medicine, University of Michigan, Ann Arbor, MI, USA (e-mail: rtipirne@med.umich.edu).

FUNDING INFORMATION The study was funded by a contract from the Michigan Department of Health and Human Services (MDHHS) to the University of Michigan to conduct an evaluation of the Healthy Michigan Plan, as required by the Centers for Medicare and Medicaid Services (CMS) through a Section 1115 Medicaid waiver.

Disclaimer

The views expressed in this article are those of the authors and do not necessarily reflect the position or policy of MDHHS or CMS.

\section{COMPLIANCE WITH ETHICAL STANDARDS:}

Conflict of Interest: The authors declare that they do not have a conflict of interest.

\section{REFERENCES}

1. Paez KA, Zhao L, Hwang W. Rising out-of-pocket spending for chronic conditions: a ten-year trend. Health Aff. 2009;28(1):15-25.

2. Patel MR, Piette JD, Resnicow K, Kowalski-Dobson T, Heisler M. Social Determinants of Health, Cost-related Nonadherence, and Cost-reducing Behaviors Among Adults With Diabetes: Findings From the National Health Interview Survey. Med Care. 2016;54(8):796-803.

3. Heisler M, Choi H, Rosen AB, et al. Hospitalizations and deaths among adults with cardiovascular disease who underuse medications because of cost: a longitudinal analysis. Med Care. 2010;48(2):87-94.

4. Hunter WG, Hesson A, Davis JK, et al. Patient-physician discussions about costs: definitions and impact on cost conversation incidence estimates. BMC Health Serv Res. 2016;16:108.

5. Alexander GC, Casalino LP, Meltzer DO. Patient-physician communication about out-of-pocket costs. JAMA. 2003;290(7):953-958.

6. Piette JD, Heisler M, Wagner TH. Cost-related medication underuse: do patients with chronic illnesses tell their doctors? Arch Intern Med. 2004;164(16):1749-1755. 